\title{
Design and Materials Selection for Environmentally Friendly Ship Propulsion System
}

\author{
Liane Roldo ${ }^{1, *}$ - Ivan Komar ${ }^{2}$ - Nenad Vulić 3 \\ ${ }^{1}$ Federal University of Rio Grande do Sul, Materials Department, Brazil \\ 2 University of Split, Faculty of Maritime Studies, Croatia \\ 3 Croatian Register of Shipping, Croatia
}

\begin{abstract}
The selection of the material regarding specific design of the stern tube journal bearings in vessels is critical taking into account the lubrication system, whether oil or water based, and the consequent lubricant leakage. Therefore, the present study examines the feasibility and the advantages of implementing water lubricated polymer shaft bearings instead of conventional white metal bearings lubricated by oil. The investigation method is related to the numerical model and the software application based on finite difference method and isoviscous model. Results, based upon data collected from three different types of actual vessels in service, have shown that power loss in polymer bearings is at least 6 times less than in conventional white metal ones indicating that polymer journal bearings are significantly more energy efficient and environmentally friendly.
\end{abstract}

Keywords: ship propulsion system, selection of materials, polymer, babbitt metal, journal bearing, software application

\section{INTRODUCTION}

General machine building industry conventionally uses metallic antifriction materials or white metal (WM) bearing alloys in friction units, known commercially as babbitt alloys. ASTM Standard B 23-00 specification covers eight typical white metal bearing alloys, the tin-based alloys and lead-based alloys [1]. Babbitts are among the most widely used materials for hydrodynamic lubricated bearings. They have excellent embeddability and conformability characteristics. They are unsurpassed in compatibility and thus prevent shaft scoring. Tin- and lead-base babbitts have a relatively low load-carrying capacity. This capacity is increased by metallurgically bonding these alloys to stronger backing materials such as steel, cast iron, or bronze [2].

Copper-lead alloys, copper-nickel, bronzes and aluminium alloys are also used. Studies of sintered self-lubricating bronze bearings have shown that additional oil at bearing considerably decreased friction coefficient especially at high velocities and pressures. In addition, it has been observed that friction coefficient decreases more by additional additive, as well as effects of loads, spindle speed and oil types influence on friction coefficient [3]. On the other hand, the Croatian Register of Shipping (CRS) rules for classification of ships in 2009 notified that cast copper alloys are recommended for applications such as shaft liners and bearing bushes [4]. Feyzullahoğlu and Şakiroğlu [5] in 2010 pointed out that aluminium alloys due to fine properties like low cost, resistance to corrosive effects, co-activation with steel shafts, high thermal conductivity, fatigue strength, lightness and workability, are entitled materials for journal bearings.

In recent years, an increasingly close attention has been given to industrial products environmental safety of the friction units of modern ships, hydraulic turbines, pumps, shipping locks, as well as oilextracting and oil-processing equipment operating in water. For this reason oil lubrication of friction units is eliminated by using such natural lubricant as water or even without lubricants [2] and [6].

Some of the water durability multiphase systems are based on polymeric materials such as thermoplastic, thermosetting, rubber and composites. Still the major problems in designing polymer bearings are to decide the optimal dimensions and material type for a long life and for obtaining lower friction and wear losses [3]. The mechanical properties generally limit the application to lightly loaded conditions and often to low speeds and conforming surfaces [2]. To Sedlaček et al. [7] a possible way to design surface texturing parameters, which would result in contact surfaces with lower friction, is by treating surface texturing as a controlled roughness.

Polypropylene (PP), polyethylene (PE), polyoxymethylene (POM), polyamide (PA), polyimide (PI), polytetrafluoroethylene (PTFE), polyurethane (PU) and polyesters with thermoplastic matrices are used to fabricate journal bearings. Also, other thermosetting materials like phenol-formaldehyde and epoxy resins, as well as composites with thermoplastic or thermosetting matrices reinforced with fillers such as carbon or glass fibre, are used as well [2], [6] and [8] to [10]. 
PP is used where higher-stiffness materials are required. It has a good environmental stress cracking resistance but is less resistant to degradation. If higher stiffness is required, reinforcement such as short glass-filled, calcium carbonate and talc can be added. PE has high toughness, ductility, excellent chemical resistance and very low water absorption. POM, PA and PI have good sliding and wear properties at low frictions. POM is a material generally used in engineering applications and is highly self-lubricating [8] and [9]. PI and its composites filled with solid lubricants and reinforced with carbon fibre show better friction reducing and antiwear behaviour under water-lubrication than under dry sliding [11].

Polyurethanes are very versatile polymers. They are used as flexible and rigid foams, elastomers, and coatings. Polyurethanes are available as both thermosets and thermoplastics. In addition, their hardness spans the range from rigid material to elastomer. Also, by providing good abrasion resistance with a low coefficient of friction and water-lubricated antifriction, cast PU's find application in roller coatings and press pads as well as gaskets, casting molds, timing belts, wear strips, liners, heels, soles, etc. [6] and [8].

Solid lubricant properties and the low friction characteristics make PTFE suitable for use in bearings, mould release devices, and anti-stick cookware [8] and [9]. For polymeric and composites materials such as epoxy resins, polyacetals, polyesters, PTFE and PI the friction coefficient frequently decreases in the presence of water while the wear rate increases. This property depends on the type of filler; at least, PTFE with different fillers may exhibit both a decrease and increase in the wear resistance [6].

Glass fibres and carbon fibres, which are short fibre reinforcements, have been successfully used to improve the strength to high pressure and wear resistance. In addition, glass fibres improve the load carrying capability and thermal conductivity. This is a positive effect to lowering wear rate of pure polymer [6] and [8].

In general, ship propulsion system design is directed to safety and functionality, where the assembly of line shafts is fundamental. In this system the shaft transfers torque of the propulsion engine to screw propeller and propulsion force from the propeller back to the thrust bearing. The most sensitive component in the propulsion shafting system is the aft stern tube bearing, which is exposed to heavy static and dynamic propeller loads exerted to the bearing surface by the propeller shaft [12]. Early arrangements used bearing materials such as lignum vitae (a very dense sort of timber) which were lubricated by seawater. Currently, most of ocean-going ships use a propeller shaft typically supported by oil lubricated white metal bearings, with forward and aft shaft seals confining the oil within the stern tube. Seals are arranged to prevent the entry of seawater and also the loss of lubricating oil from stern tube bearing [13]. The Marine Environment Protection Committee in its document MEPC 58/INF.22 reported that, regarding seal proper function, seal manufacturers indicate the seal must leak at the shaft/seal interface (aft-to-sea, forward-to-bilges) in order for the seal to function properly. In addition, debris such as rope caught on a ship's rotating shaft can also damage the aft seal, allowing stern tube oil to flow into the sea. Typical ocean-going ship stern tubes contain about 1500 liters of oil so, even at a conservative leakage rate of $61 /$ day, stern tube oil pollution from normal operations can be estimated to be over 80 million liters annually [13].

Environmentally friendly materials and practices are other important issues to be taken into consideration. The International Maritime Organization (IMO) by the International Convention for the Prevention of Pollution from Ships (MARPOL) Annex I - Regulations for the prevention of pollution by oil, revised in 2003, covers prevention of pollution by oil from operational measures as well as from accidental discharges. Also, the recent amendments to MARPOL Annex VI Regulations for the prevention of air pollution from ships, make mandatory the Energy Efficiency Design Index (EEDI), for new ships, and the Ship Energy Efficiency Management Plan (SEEMP) for all ships. The regulations apply to all ships of 400 gross tonnage and above and are planned to enter into force on 1st January 2013 [14] to [16].

From the environmental aspect there is no doub that the use of modern polymer bearings, rather than the usual white metal ones, eliminates the possibility of pollution due to oil leakage. Therefore, the present study examines practicability and advantages of polymer propeller shaft bearings compared to conventional white metal bearings investigated on real ships.

\section{MATERIALS AND METHODS}

Five different materials currently used for ship journal bearings were considered for the models calculation: One tin based alloy was used as comparative metallic material towards four different types of polymers.

Table 1 presents the materials elastic modulus and Poisson's ratio obtained from literature [2] and [8]. 
Table 1. Mechanical properties of materials used in ships stern tube journal bearing design

\begin{tabular}{lcc}
\hline \multicolumn{1}{c}{ White Metal Material } & $\begin{array}{c}\text { Young's Modulus } \\
{[\mathrm{MPa}]}\end{array}$ & $\begin{array}{c}\text { Poisson's } \\
\text { ratio }\end{array}$ \\
\hline Tin-base babbitt (White Metal) & 55,000 & 0.35 \\
\hline Polymeric Material & & \\
\hline $\begin{array}{l}\text { Thermoplastic polyether polyurethane } \\
\text { elastomer (polyether PU) }\end{array}$ & 253 & 0.467 \\
\hline $\begin{array}{l}\text { Carbon reinforced composite with an } \\
\text { epoxy matrix (CRE) }\end{array}$ & 10,000 & 0.25 \\
\hline $\begin{array}{l}\text { Flexible-chain polyamide type 6 (PA } \\
\text { type 6) }\end{array}$ & 3,530 & 0.36 \\
\hline \begin{tabular}{l} 
Polytetrafluoroethylene unfilled (PTFE) \\
\hline
\end{tabular} & 552 & 0.46 \\
\hline
\end{tabular}

\subsection{Calculation Model}

According to Jocanović et al. [17] in the process of hydraulics systems design various software simulation systems are used. However, the increase of efficiency of the designed hydraulic systems can be achieved in two ways: by making design modifications based on reliability theory or based on monitoring of system operating parameters. In this case, to determine the properties of the white metal bearing oil lubricant film and its load Reynolds differential equation is used, which is solved, for the real conditions, by the numerical method of finite difference [18]. This numerical method relies on the fact that a function can be represented with a sufficient accuracy over a small range by a quadratic expression. To solve the Reynolds equation (Eq. (1)) (which is expressed in terms of lubricant film thickness $h$, pressure $p$, journal velocity $v_{j}$ and lubricant dynamic viscosity $\eta$ ) by finite difference method the equation is transformed into its dimensionless form. Assuming that $\eta=$ constant for a given temperature, the Reynolds equation describes lubricant pressure distribution as a function of journal speed, bearing geometry, and lubricant viscosity in stationary hydrodynamic lubrication in journal bearing:

$$
\frac{\partial}{\partial x}\left(h^{3} \frac{\partial p}{\partial x}\right)+\frac{\partial}{\partial y}\left(h^{3} \frac{\partial p}{\partial y}\right)=6 v_{j} \eta \frac{\partial h}{x}
$$

In journal bearings the friction coefficient is the ratio of circumferential friction force divided by the load.

$$
\mu=\frac{F_{t}}{W}=\frac{\int_{0}^{L} \int_{0}^{2 \pi R_{B}} \tau d x d y}{\int_{0}^{L} \int_{0}^{2 \pi R_{B}} p d x d y},
$$

where $\mu$ is coefficient of friction, $F_{t}$ friction force [N], $W$ bearing radial load $[\mathrm{N}]$ and $\tau$ shear stress $[\mathrm{Pa}]$.

Power loss in the bearing can be calculated by equation:

$$
P_{l o s s}=\mu \cdot W \cdot v_{j}, \quad[W],
$$

where $v_{j}$ is journal velocity $[\mathrm{m} / \mathrm{s}]$.

In another way by frictional power in a bearing or the amount of heat generated which is used for model validation measuring bearing working temperature on a real ship:

$$
P_{\text {th }}=\rho \cdot c_{v} \cdot Q \cdot\left(T_{\text {out }}-T_{\text {in }}\right), \quad[\mathrm{W}],
$$

where $T_{\text {in }}$ is bearing inlet lubricant temperature $\left[{ }^{\circ} \mathrm{C}\right]$, $T_{\text {out }}$ bearing outlet lubricant temperature $\left[{ }^{\circ} \mathrm{C}\right], P$ density of lubricant $\left[\mathrm{kg} / \mathrm{m}^{3}\right], c_{v}$ specific heat capacity of the lubricant $[\mathrm{J} / \mathrm{kgK}]$ and $Q$ total lubricant flow rate $\left[\mathrm{m}^{3} / \mathrm{s}\right]$.

Unlike white metal, polymer bearing works in EHL regime, in which the elastic deformation of contact surfaces has a significant impact on the minimum thickness of the created lubricant film. This lubrication regime is described by Hamrock and Dowson expressions for calculating the minimum and central thickness of the lubricant film under the conditions of the bearing EHL regime, as follows:

$$
\begin{aligned}
& \tilde{H}_{\text {min }}=8.7 G_{\mathrm{E}}^{0.67}\left(1-0.85 \mathrm{e}^{-0.31 \mathrm{k}}\right)\left(U_{\text {red }} / W\right)^{2}, \\
& \tilde{H}_{\mathrm{c}}=11.15 G_{\mathrm{E}}^{0.67}\left(1-0.72 \mathrm{e}^{-0.28 \mathrm{k}}\right)\left(U_{\text {red }} / W\right)^{2},
\end{aligned}
$$

where $\tilde{H}_{\min }$ is nondimensional minimal film thickness, $\tilde{H}_{c}$ nondimensional central film thickness, $U_{\text {red }}$ nondimensional speed, $W$ nondimensional load parameter, $G_{E}$ nondimensional elasticity and $k$ nondimensional ellipticity.

Starting from the theory available in the literature for modeling HL and EHL lubrication, an own computer program has been developed for the calculation of HL and EHL bearings lubrication as well as lubricant flow through the bearing. Calculation methods and models have been validated comparing with collected data from three types of the ships in service.

\subsection{Calculation Parameters}

For the actual power loss $[\mathrm{kW}]$ calculations software composed of two modules S1lpartialRJB and S1lisoviscRJB was developed [19]. Computational models have been verified experimentally based upon 
data of stern tube bearing operating temperatures obtained from three types of ships (bulk carrier, container ship and RO-RO catamaran passenger ship).

Ship engines speed (revolutions per minute) were within interval of 30 to $121 \mathrm{rpm}$ with a step of 10 for bulk carrier, 22 to $109 \mathrm{rpm}$ with a step of 10 for container ship and 100 to $608 \mathrm{rpm}$ with a step of 100 for catamaran.

For the white metal oil lubricated bearing a hydrodynamic lubrication model was used S11partialRJB [19]. The core of numerical calculations (finite difference methods for the numerical solution of Reynold's equation) was based upon Matlab program partial taken from Stachowiak and Batchelor [18]. The polymeric water lubricated bearings, due to elastic deformation of the lubricated surfaces, needed a different approach: i.e. an elastohydrodynamic lubrication (EHL) program. S11isoviscRJB calculates polymer bearing elastic deflection based on Hamrock and Schmid [2] elastohydrodynamic lubrication analysis of isoviscous-elastic body lubrication regimes [18].

Validation of these models is based upon the actual bearing temperatures for different driving regimes obtained from real ships in service. These ships were a bulk carrier of 50,000 deadweight tonnage (DWT), a container ship of 11,000 twentyfoot equivalent units (TEU) and a catamaran of 496 gross tonnage (GT).

Parameters of the lubricants to ships are:

1. Oil density $\rho=910 \mathrm{~kg} / \mathrm{m}^{3}$, kinematic viscosity at

$30{ }^{\circ} \mathrm{C}$ is $v=175 \mathrm{~mm}^{2} / \mathrm{s}$ and specific heat capacity $1922 \mathrm{~J} / \mathrm{kgK}$.

2. Average seawater density $\rho=1025 \mathrm{~kg} / \mathrm{m}^{3}$ at average temperature of $15^{\circ} \mathrm{C}$, considering trading area of the actual ships. At this condition the seawater as lubricant has kinematic viscosity of $1.1843 \mathrm{~mm}^{2} / \mathrm{s}$ and dynamic viscosity of $1.21 \cdot 10^{-3}$ $\mathrm{Pa} \cdot \mathrm{s}$.

Table 2 presents relevant ship design parameters for power loss calculation using white metal bearing and polymer bearing of the aft stern tube for bulk carrier, container ship and catamaran respectively.
Additionally, based upon the results of the calculation the elastic line of shafting, the bulk carrier bearing was under a constant load of $225 \mathrm{kN}$, the container ship constant bearing load was $1325 \mathrm{kN}$ and catamaran bearing under constant load of $3.6 \mathrm{kN}$ with an arc bearing angle of $360^{\circ}$.

Further analysis of polymer stern tube bearings installation instead one of white metal is based on the analysis of fuel saving within the specified period of exploitation of ships of twenty years, and based on consumption of fuel.

Fuel consumption $(C f)$ of these items is based on the data from IMO of the average period of exploitation of the ship of 330 days per year and can be calculated by the formula [13] and [19]:

$$
C_{f}=P_{\text {loss }} \cdot m_{s} \cdot \frac{24 t_{\text {exp }}}{1000} \quad[\mathrm{~kg} / \mathrm{year}]
$$

where $P_{\text {loss }}$ is power loss in stern tube bearings due to hydrodynamic friction $[\mathrm{kW}], m_{\mathrm{s}}$ specific fuel oil consumption (SFOC) of the propulsion engine [g/kWh], and $t_{\text {exp }}$ number of days of ship exploitation per year.

\section{RESULTS AND DISCUSSION}

\subsection{Comparative Parameters Results for White Metal and Polymer Bearing}

Figs. 1 to 3 show the comparison of power losses in the aft stern tube bearing in case of white metal and polymer applications as bearing material for bulk carrier, container ship and catamaran ship respectively.

As shown in Fig. 1 the bulk carrier power loss due to friction of the polymeric bearings is approximately 6 (polyether PU) to 9 times (CRE) smaller than the power loss in the bearing of the white metal at a maximum speed of the propeller shaft of $121 \mathrm{rpm}$.

Fig. 2 shows that the container ship power loss due to friction in the polyether PU bearing is about 6 times less and the carbon reinforced epoxy is nearly 8.5 times less than the power loss in the bearing of the

Table 2. Design parameters for the aft stern tube white metal and polymer bearing of the bulk carrier, container ship and catamaran

\begin{tabular}{|c|c|c|c|c|c|c|c|c|}
\hline \multirow[b]{2}{*}{ Description } & \multirow[b]{2}{*}{ Parameters } & \multirow[b]{2}{*}{ Dimensions } & \multicolumn{3}{|c|}{ White metal bearing } & \multicolumn{3}{|c|}{ Polymer bearing } \\
\hline & & & $\begin{array}{c}\text { Values } \\
\text { Bulk } \\
\text { carrier }\end{array}$ & $\begin{array}{c}\text { Values } \\
\text { Container } \\
\text { ship }\end{array}$ & $\begin{array}{c}\text { Values } \\
\text { Catamaran }\end{array}$ & $\begin{array}{c}\text { Values } \\
\text { Bulk } \\
\text { carrier }\end{array}$ & $\begin{array}{c}\text { Values } \\
\text { Container } \\
\text { ship }\end{array}$ & $\begin{array}{c}\text { Values } \\
\text { Catamaran }\end{array}$ \\
\hline Bearing nominal diameter & $D_{B}$ & $\mathrm{~mm}$ & 469.8 & 991.2 & 120.22 & 516.59 & $1,072.92$ & 120.36 \\
\hline Bearing length & $L$ & $\mathrm{~mm}$ & 950 & 2030 & 240 & 950 & 2030 & 240 \\
\hline Bearing diametral clearance & $Z$ & $\mathrm{~mm}$ & 0.8 & 1.2 & 0.22 & 1.59 & 2.92 & 0.36 \\
\hline Journal diameter & $D_{i}$ & $\mathrm{~mm}$ & 469 & 990 & 120 & 469 & 990 & 120 \\
\hline
\end{tabular}




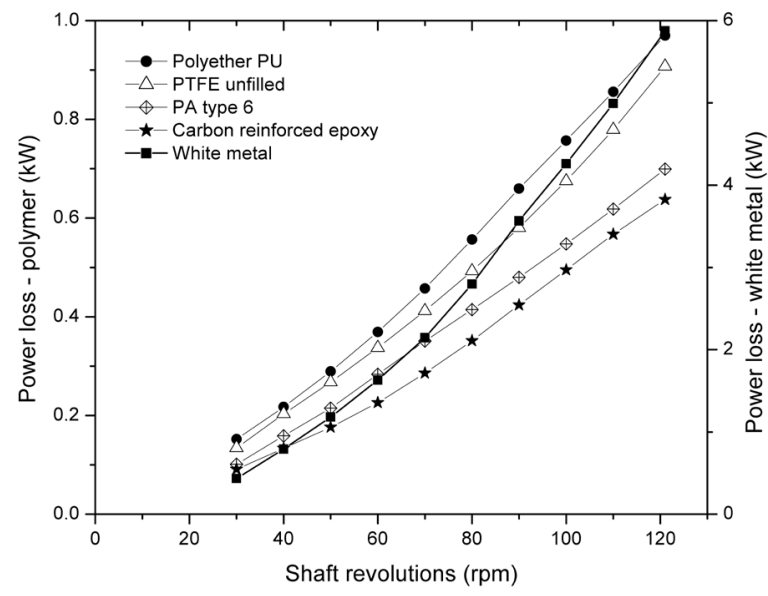

Fig. 1. Comparison of bulk carrier power loss of stern tube WM bearing versus various polymer bearings at propeller shaft revolution from 30 to $121 \mathrm{rpm}$

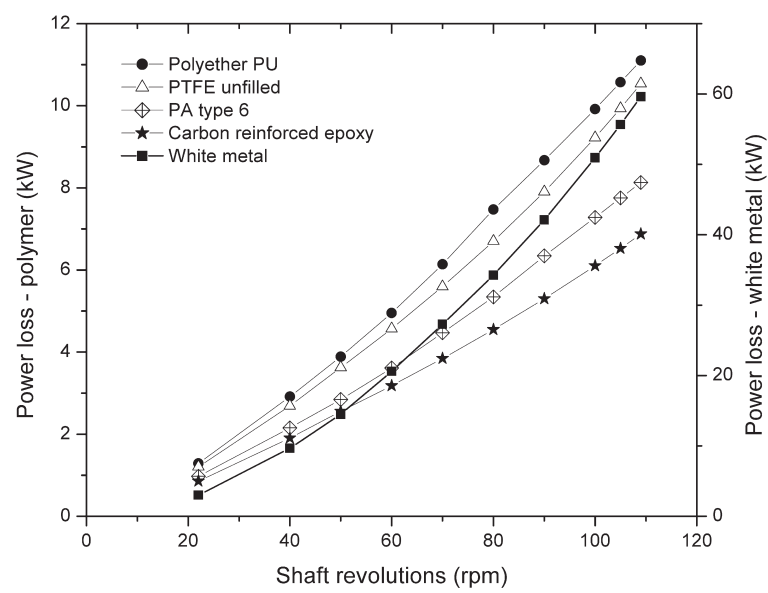

Fig. 2. Comparison of container ship power loss of stern tube WM bearing versus various polymer bearings at propeller shaft revolution from 22 to $109 \mathrm{rpm}$

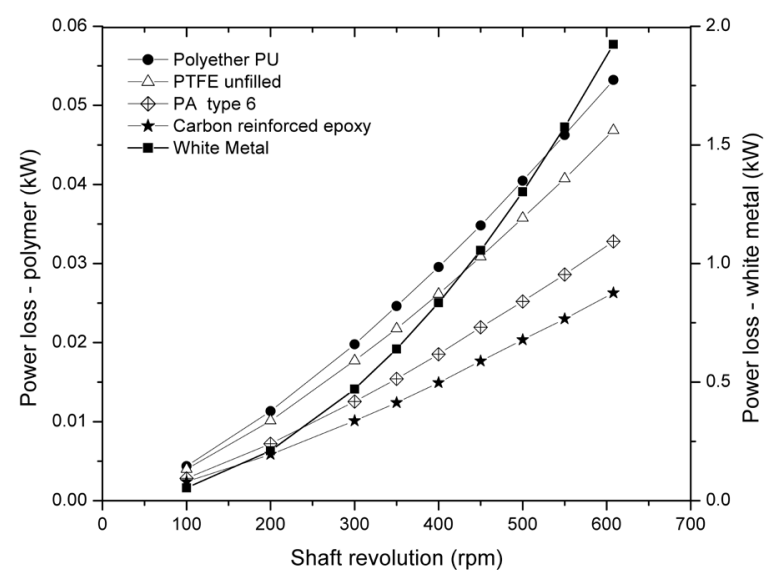

Fig. 3. Comparison of catamaran power loss of stern tube WM bearing versus various polymer bearings at propeller shaft revolution from 100 to $608 \mathrm{rpm}$ white metal at a maximum speed of the propeller shaft of $109 \mathrm{rpm}$.

As presented in Fig. 3 that the catamaran ship power loss due to friction in the polyether PU bearing is about 36 times less and the carbon reinforced epoxy is nearly 73 times less than the power loss in the bearing of the white metal at a maximum speed of the propeller shaft of $608 \mathrm{rpm}$.

\subsection{Comparative Results of Energy Efficiency for White Metal and Polymer Bearing}

Table 3 presents the overall comparative analysis of fuel consumption due to power loss because of hydrodynamic friction in the stern tube bearings, and fuel savings in the case of application of polymer bearings instead of white metal.

The average specific fuel consumption of the propulsion engines based on the manufacturer data for bulk carrier and container ship is $180 \mathrm{~g} / \mathrm{kWh}$, and for catamaran is $210 \mathrm{~g} / \mathrm{kWh}$.

Table 3. Comparative analysis of fuel consumption and power loss for white metal (WM) and polymer (Pol.) bearings

\begin{tabular}{|c|c|c|c|}
\hline & \multicolumn{3}{|c|}{ Ship Type } \\
\hline \multicolumn{4}{|c|}{ Data of power loss in stern tube bearing due to friction (W) } \\
\hline Bearing material & $\begin{array}{c}\text { Bulk } \\
\text { carrier }\end{array}$ & $\begin{array}{l}\text { Container } \\
\text { ship }\end{array}$ & Catamaran \\
\hline White metal - WM & 5875 & 59617 & 1923 \\
\hline Polymer - Pol. & 970 & 11103 & 53 \\
\hline $\begin{array}{l}\text { Power loss difference } \\
\text { WM - Pol. }\end{array}$ & 4905 & 48514 & 1870 \\
\hline \multicolumn{4}{|c|}{ Data of fuel consumption based on the difference in power loss (WM) } \\
\hline & $\begin{array}{c}\text { Bulk } \\
\text { carrier }\end{array}$ & $\begin{array}{l}\text { Container } \\
\text { ship }\end{array}$ & Catamaran \\
\hline SFOC $[\mathrm{g} / \mathrm{kWh}]$ & 180 & 180 & 210 \\
\hline Daily fuel consumption $[\mathrm{kg}]$ & 21.2 & 209.6 & 9.4 \\
\hline Exploitation days per year & 330 & 330 & 330 \\
\hline Yearly fuel consumption [t] & 7 & 69 & 3 \\
\hline $\begin{array}{l}\text { Fuel consumption per } 20 \\
\text { years * }[\mathrm{t}]\end{array}$ & 140 & 1380 & 60 \\
\hline
\end{tabular}

* Represents a saving of fuel in the case of application of polymer instead of white metal stern tube bearing.

The power loss is caused by hydrodynamic friction in the stern tube bearings for analyzed ships (fuel savings per item) using polyether PU instead of the conventional white metal bearings. Table 4 presents the projecting results of fuel saving on a sample of 1000 ships per type over 20 years of exploitation for the application of polymer bearing.

Owing to projecting results for the application of polymer sterntube bearings at the global level on 
Table 4. Projecting results of fuel saving for the application of polymer stern tube bearings at global level on a sample of 1000 ships per type in 20 years of exploitation

\begin{tabular}{lccc}
\hline Ship type & $\begin{array}{c}\text { Fuel consumption } \\
\text { per 20 years per ship }[\mathrm{t}]\end{array}$ & $\begin{array}{c}\text { Fuel consumption } \\
\text { per 20 years per 1000 ships [t] }\end{array}$ & Total [t] \\
\hline Bulk carrier & 140 & 140,000 & $1,580,000$ \\
\hline Container ship & 1,380 & $1,380,000$ & \\
\hline Catamaran & 60 & 60,000 & \\
\hline
\end{tabular}

Table 5. Projected results of oil leakage from the seal in normal operation of ocean-going vessels equipped with WM stern tube bearings of a sample of 1000 ships per type within the period of 20 years

\begin{tabular}{|c|c|c|c|c|}
\hline Ship type & $\begin{array}{l}\text { Stern tube oil leakage rate } \\
\text { per day [liter] }\end{array}$ & $\begin{array}{l}\text { Stern tube oil leakage rate } \\
\text { per ship per } 20 \text { years } \\
\text { of exploitation [liter] }\end{array}$ & $\begin{array}{l}\text { Stern tube oil leakage rate } \\
\text { per } 1000 \text { ship per } 20 \text { years } \\
\text { of exploitation [liter] }\end{array}$ & $\begin{array}{c}\text { Total stern tube } \\
\text { oil leakage } \\
\text { [liter] }\end{array}$ \\
\hline Bulk carrier & 6 & 39,600 & $39,600,000$ & \multirow{3}{*}{$158,400,000$} \\
\hline Container ship & 12 & 79,200 & $79,200,000$ & \\
\hline Catamaran & 6 & 39,600 & $39,600,000$ & \\
\hline
\end{tabular}

a sample of 3000 ships in the exploitation period of 20 years, it can be observed from Table 4 that the use of polymer sterntube bearings realises significant savings in fuel and oil consumption in all three ships taken into consideration.

Table 5 shows the projected results of oil leakage during normal operation of ships equipped with white metal stern tube bearings at global level using a sample of 3000 ships in 20 years of exploitation.

Oil consumption from the journal seal is controlled to the minimum acceptable to maintain the propulsion system functional, however by design it is essential to have oil at the mating surfaces. Oil consumption is always lost directly to the sea thus contaminating the environment. As per Lloyd's Register Class Society Seal Type Approvals data, sterntube oil leakage rate amounts to 6 liters/day from normal operations based on seals in a laboratory condition running in clean and controlled environments [20]. In addition to fuel efficiency oil leakage into the seawater is also an important issue to be taken into consideration. Tabel 5 shows that the use of water lubricated polymer bearings eliminates sea contamination caused by propulsion system seal leakage.

\section{CONCLUSIONS}

The analysis focuses on the value of effective power loss in sterntube bearings due to viscous friction in the lubricant film comparing white metal bearings with polymer ones. Therefore, reduction of the system power loss is achieved using lubricant with low viscosity such as seawater in case of polymer bearing.

Comparing the power loss of the sterntube polymeric materials with the white metal and taking into consideration the bulk carrier, container ship and catamaran ship, it is possible to verify that the actual power loss is, at least 6 times less for bulk carrier and container ship and 36 times less for catamaran (due to high nominal shaft rpm) using sterntube polymer bearings.

Among polymeric bearing materials it was observed that the carbon reinforced composite with an epoxy matrix works more efficiently than other calculated polymer applications. Another important finding is that the overall bulk carrier power loss is 10 times smaller compared to the container ship. This fact is attributed to the sterntube system design as the bulk carrier has only one aft sterntube bearing, while container ship has aft and forward sterntube bearings due to bigger shaft dimension and respectively higher bearing load.

Projecting the results of the economic reason for the application of polymer sterntube bearings at the global level on a sample of 3000 ships (1000 of each type) in the exploitation period of 20 years, $1,580,000$ tonnes of fuel and 158,400,000 liters of lubricant oil may be saved. Therefore, the use of polymer sterntube bearings shows the possibility of significant savings in fuel and oil consumption. This would achieve not only significant financial savings but also improved energy efficiency of the ship. Therefore, it would also contribute to meeting the IMO ship environment requirements and related energy efficiency design index. Implementation of these models and a materials selection approach can lead even to a solid basis to propose a different design approach to ship designers: polymer bearings instead of white metal bearings. There may be some drawbacks to this solution, such as the need for careful machining of shafts 
and the bearings, necessity of proper preparation (e.g. filtration) of sea-water, etc. that have not been considered within the scope of this paper. The use of polymer sterntube bearings shows the possibility of significant savings in fuel and oil consumption and contributes the environment ship requirements and related energy efficiency design index. Furthermore, the analysis defined the optimisation point, i.e. the time period after which the payment of higher initial investment for installation of polymer sterntube bearings will show to be reasonable. This gives the possibility to the ship-owners to take a decision whether and when it is worthwhile mounted polymer sterntube bearing instead of the white metal, based on the scientifically proven methodology.

\section{ACKNOWLEDGEMENTS}

Liane Roldo thanks the support from Brazilian Research Agency CNPq - Conselho Nacional de Desenvolvimento Tecnológico.

\section{REFERENCES}

[1] ASTM B 23-00. Standard Specification for White Metal Bearing Alloys 2010, ASTM International, West Conshohocken.

[2] Hamrock, B.J., Schmid, S.R., Jacobson, B.O. (2004). Fundamentals of Fluid Film Lubrication. $2^{\text {nd }}$ ed. Marcel Dekker, New York, Basel, DOI:10.1201/9780203021187.

[3] Ünlü, B.S., Atik, E. (2007). Determination of friction coefficient in journal bearings. Materials \& Design, vol. 28, no. 3. p. 973-977, DOI:10.1016/j. matdes.2005.09.022.

[4] Rules for the Classification of Ships 2009, part 25. Croatian Register of Shipping, Split.

[5] Feyzullahoğlu, E., Şakiroğlu, N. (2010). The wear of aluminium-based journal bearing materials under lubrication. Materials \& Design, vol. 31, no. 5, p. 2532-2539, DOI:10.1016/j.matdes.2009.11.037.

[6] Ginzburg, B.M., Tochil'ikov, G.D. Bakhareva, V.E., Anisimov, A.V., Kireenko, O.F. (2006). Polymeric Materials for Water-Lubricated Plain Bearings. Russian Journal of Applied Chemistry, vol. 79, no. 5, p. 695706, DOI:10.1134/S1070427206050016.

[7] Sedlaček, M., Vilhena, L.M.S., Podgornik, B., Vižintin, J. (2011). Surface Topography Modelling for Reduced Friction. Strojniški vestnik - Journal of Mechanical Engineering, vol. 57, no. 9, p. 674-680, DOI:10.5545/ sv-jme.2010.140.
[8] Harper, C.A. (2002). Handbook of Plastics, Elastomers, and Composites. $4^{\text {th }}$ ed. McGraw-Hill Handbook, New York.

[9] Ünlü, B.S., Atik, E., Koksal, S. (2009) Tribological properties of polymer-based journal bearings. Materials \& Design, vol. 30, no. 7, p. 2618-2622, DOI:10.1016/j. matdes.2008.11.018.

[10] Bielinski, D.M., Glab, P., Slusarski, L. (2006). New approach to study tribological properties of polymer materials. A case of car windshield wipers. Journal of Achievements in Materials and Manufacturing Engineering, vol. 15, no. 1-2, p. 71-78.

[11] Jia, J.H., Zhou, H.D., Gao, S.Q., Chen, J.M. (2003). A comparative investigation of the friction and wear behavior of polyimide composites under dry sliding and water-lubricated condition. Materials Science and Engineering: $A$, vol. 356, no. 1-2, p. 48-53, DOI:10.1016/S0921-5093(03)00052-2.

[12] Komar, I., Vulić. N., Antonić, R. (2009). Specifics of shafting alignment for ships in service. Promet Traffic\&Transportation, vol. 121, no. 5, p. 349-357, DOI:10.7307/ptt.v21i5.250.

[13] Use of seawater lubricated tube bearings to eliminate sterntube oil pollution from ships Resolution MEPC 58/INF 22. IMO 2008. (2008). Marine Environment Protection Committee, International Maritime Organization, London.

[14] International Convention for the Prevention of Pollution from Ships. Annex I Regulations for the prevention of pollution by oil (2003). International Maritime Organization, London.

[15] Annex VI Regulations for the prevention of air pollution from ships (2005). International Maritime Organization, London.

[16]Energy Efficiency Design Index. Resolution MEPC.203(62) (2011). International Maritime Organization, London.

[17] Jocanović, M., Šević, D., Karanović, V., Beker, I., Dudić, S. (2012). Increased efficiency of hydraulic systems through reliability theory and monitoring of system operating parameters. Strojniški vestnik Journal of Mechanical Engineering, vol. 58, no. 4, p. 281-288, DOI:10.5545/sv-jme.2011.084.

[18] Stachowiak, G.W., Batchelor, A.W. (2005). Engineering Tribology, 3rd ed. Elsevier Butterworth-Heinemann, Oxford, p. 728-736.

[19] Komar, I. (2012). Contribution to the selection methodology of the most convenient marine propulsion stern tube bearings, Ph.D Thesis, Faculty of Maritime Studies, Rijeka.

[20] Higgenbottom, A. (2003). Coastguard non-polluting sterntube sealing system. RINA International Conference for the Design and Operation of Container Ships, London, p. 53-60. 